\title{
Sex specific impact of different obesity phenotypes on the risk of incident hypertension: Tehran lipid and glucose study
}

Maryam Kabootari ${ }^{1,2}$, Samaneh Akbarpour ${ }^{3}$, Fereidoun Azizi ${ }^{4}$ and Farzad Hadaegh ${ }^{2 *}$

\begin{abstract}
Background: To investigate the association between different obesity phenotypes and the risk of incident hypertension among both genders.

Methods: The study population included 3659 Iranians (men =1540), aged $\geq 20$ years free of hypertension at baseline. Participants were classified into six categories of body mass index (BMI)-metabolic health status, in which unhealthy metabolic status was defined based on the presence of $>1$ component of metabolic syndrome (MetS) using the joint interim statement (JIS) criteria or the presence of insulin resistance (IR). The association between different obesity phenotypes and incident hypertension was assessed using multivariate Cox's proportional hazard models adjusted for age, current smoking, low physical activity, diabetes mellitus, family history of premature cardiovascular disease, estimated glomerular filtration rate, phase of recruitment, BMI and systolic blood pressure, considering metabolically healthy normal weight group as the reference.
\end{abstract}

Results: After a median follow-up of 11.6 years 1122 participants (men $=493$ ) experienced hypertension. Using JIS criteria, a significant higher risk of hypertension was observed among metabolically healthy obese and well as metabolically unhealthy groups among men in the age adjusted model; however, a significant higher risk in the fully adjusted model was seen among women in the metabolically healthy obese [hazard ratio (HR) 95\% confidence interval (CI) 1.96(1.16-3.32)] as well as metabolically unhealthy normal weight [1.98(1.37-2.86)], overweight [2.08(1.49-2.90)] and obese [2.06(1.27-3.30)] groups. Using insulin sensitive normal weight group as the reference, among men, being overweight or obese with and without IR was significant predictors of incident hypertension in the age adjusted model; however, among women, insulin resistant overweight [1.46(1.06-2.02)] and obese groups, [1.63(1.01-2.62)] showed significant risk in the fully adjusted model.

Conclusion: We concluded that first, there was significant difference between genders in the associations between obesity phenotypes and incident hypertension. Second, in general, metabolic status defined by MetS components as compared to IR could do better in identifying high risk women for hypertension. Third, women populations who are metabolically healthy obese using MetS definition or those with either $>1$ component of metabolic syndrome or overweight/obese ones with IR should be prioritized for implementing urgent preventive strategies against hypertension focusing on lifestyle changes.

Keywords: Obesity phenotype, Hypertension, Insulin resistance, Metabolic syndrome

\footnotetext{
* Correspondence: fzhadaegh@endocrine.ac.ir

${ }^{2}$ Prevention of Metabolic Disorders Research Center, Research Institute for Endocrine Sciences, Shahid Beheshti University of Medical Sciences, P.O. Box: 19395-4763, No. 24, Parvaneh Street, Velenjak, Tehran, Iran

Full list of author information is available at the end of the article
}

(C) The Author(s). 2019 Open Access This article is distributed under the terms of the Creative Commons Attribution 4.0 International License (http://creativecommons.org/licenses/by/4.0/), which permits unrestricted use, distribution, and reproduction in any medium, provided you give appropriate credit to the original author(s) and the source, provide a link to the Creative Commons license, and indicate if changes were made. The Creative Commons Public Domain Dedication waiver (http://creativecommons.org/publicdomain/zero/1.0/) applies to the data made available in this article, unless otherwise stated. 


\section{Introduction}

Obesity is a serious public health concern worldwide [1]. Both general and central obesity show an increasing trend particularly during recent years among Iranian populations in the background of Westernization of diets and sedentary lifestyle [2]. Individuals with obesity are at increased risk of type 2 diabetes, hypertension, cancer and cardiovascular diseases(CVD) [3]. Similarly, hypertension is an important leading cause of CVD and all-cause mortality with population attributable fractions (PAFs) of 21.62 and $17.13 \%$ for CVD and all-cause mortality, respectively, among Iranian populations [4].

Different subtypes of obesity have been defined based on combinations of obesity and metabolic components [5]. A sub-group of metabolically healthy overweight or obese individuals, has been described; however, its benign nature regarding development of CVD and all-cause mortality events remains unclear [6, 7]. Moreover, inconsistent definitions of metabolic health and obesity are used in different studies [8]; recently, an association between different obesity phenotypes including metabolically healthy obesity and development of hypertension has been described in few studies mostly conducted in East Asia and one study in the Europe [9-13]. Furthermore, to the best of our knowledge, except for one study performed only among men [13], all studies have been conducted in pooled samples and data regarding the effect of sex on the outcome is lacking.

Considering the high prevalence and incidence of obesity [14] and hypertension among a Middle Eastern populations [15], we aimed to investigate the association between different obesity phenotypes and the development of hypertension, separately in each gender considering 2 different definitions of unhealthy metabolic status i.e., the presence of more than 1 component of metabolic syndrome (MetS) or the presence of insulin resistance (IR) $[16,17]$ over a long term follow-up in the population-based cohort of the Tehran Lipid and Glucose Study (TLGS).

\section{Methods}

\section{Study population}

The TLGS is an ongoing prospective longitudinal population-based study conducted on a representative sample of Tehran, the capital city of Iran. The main aim of the study was to investigate the risk factors and outcomes of non-communicable disease. TLGS recruitment was conducted in two phases, i.e. the first, (1999-2001) and the second (2002-2005) phases and is planned to continue for at least 20 years with follow-up exams with an approximately 3-year intervals; i.e. the third phase: 2005-2008, fourth phase: 2009-2011 and the fifth phase: 2012-2015. Study protocol has been described in more detail elsewhere [18].
For the present study, we considered the data of 5454 participants, aged $\geq 20$ years, who had measurements of insulin level at baseline. After excluding subjects with prevalent hypertension at baseline $(n=1024)$, prevalent CVD $(n=126)$, women who were pregnant during any examination $(n=55)$ and those with body mass index $(\mathrm{BMI})<18.5 \mathrm{~kg} / \mathrm{m}^{2}(n=108), 4141$ participants were enrolled the current study. Moreover, other exclusions were those with missing data of BMI $(n=105)$, hypertension status $(n=76)$, MetS components $(n=98)$ and other covariates including smoking, family history of premature CVD, serum creatinine level, physical activity status ( $n=139)$, and those without any follow-up data $(n=64)$, leaving 3659 participants for the final analysis. The study was approved by the ethics committee of the Research Institute for Endocrine Sciences and the ethical principles of the Helsinki Declaration were followed.

\section{Clinical and laboratory measurements}

At baseline, participants were interviewed by trained personnel using pretested questionnaires. Information on age, gender, smoking habits, medical and drug history, and family history of premature CVD were collected. Weight was measured in light clothing without shoes, using a digital scale (Seca 707, Seca Corp., Hanover, MD, USA; range $0.1-150 \mathrm{~kg}$ ) to the nearest $0.1 \mathrm{~kg}$. Height was measured in a standing position without shoes using an unstretched tape meter, while shoulders were in normal alignment. BMI was measured as weight $(\mathrm{kg})$ divided by square of height $\left(\mathrm{m}^{2}\right)$. Waist circumference (WC) was measured at the umbilical level to the nearest $0.1 \mathrm{~cm}$ over light clothing, using a tape meter, with no pressure on body surface. Blood pressure was taken twice after 15-min resting in sitting position, using a standardized mercury sphygmomanometer on the right arm, and mean of two measurements was considered as the subject's blood pressure. Physical activity level was assessed with the Lipid Research Clinic (LRC) questionnaire in the first phase of the TLGS [19]; due to some inaccuracies of the LRC, it was replaced from the second phase by the Modifiable Activity Questionnaire (MAQ), a questionnaire which measures all three forms of activities including leisure time, job, and household activities in the past year. [20].

After $12 \mathrm{~h}$ overnight fasting a venous blood sample was drawn from all study participants. Fasting plasma glucose (FPG), 2-h post challenge plasma glucose (2 h-PCPG) with 75 g glucose, total cholesterol (TC), High density lipoprotein-cholesterol (HDL-C) and triglyceride (TG) levels were measured using methods described before. [18] Insulin level was measured using the enzyme-linked immune sorbent assay (Mercodia, Uppsala, Sweden) with inter- and intra assay coefficients of variations of 3.3 and $1.4 \%$, respectively. 


\section{Definition of terms}

Obesity phenotype was defined based on the WHO BMI definition as follows: Normal weight $\mathrm{BMI}<25 \mathrm{~kg} / \mathrm{m}^{2}$, overweight $\mathrm{BMI} \geq 25$ and $<30 \mathrm{~kg} / \mathrm{m}^{2}$ and obese $\mathrm{BMI} \geq$ $30 \mathrm{~kg} / \mathrm{m}^{2}$. Hypertension was defined as systolic blood pressure $(\mathrm{SBP} \geq 140 \mathrm{~mm}-\mathrm{Hg})$ and/or diastolic blood pressure $(\mathrm{DBP} \geq 90 \mathrm{~mm}-\mathrm{Hg}$ ) or under treatment with anti-hypertensive drugs. Metabolic abnormalities were defined by the presence of MetS components. MetS components for this study included the criteria proposed by the Joint Interim Statement (JIS) [16] as follows: (1) central obesity defined as $\mathrm{WC} \geq 90 \mathrm{~cm}$, the cut off proposed for the adult Iranian population for both sexes $[21,22]$; (2) $\mathrm{FPG} \geq 100 \mathrm{mg} / \mathrm{dl}(5.6 \mathrm{mmol} / \mathrm{l})$ or drug treatment; (3) low serum HDL-C defined as $<50 \mathrm{mg} / \mathrm{dl}(1.29$ $\mathrm{mmol} / \mathrm{l})$ in women and $<40 \mathrm{mg} / \mathrm{dl}(1.03 \mathrm{mmol} / \mathrm{l})$ in men or drug treatment; (4) elevated blood pressure defined as $\mathrm{SBP} \geq 130 \mathrm{mmHg}$ or $\mathrm{DBP} \geq 85 \mathrm{mmHg}$ or antihypertensive drug treatment; and (5) hypertriglyceridemia, defined as fasting TG levels $\geq 150 \mathrm{mg} / \mathrm{dl}(1.7 \mathrm{mmol} / \mathrm{l})$ or drug treatment for elevated TG level. In the present study, participants were considered as metabolically healthy if they had $\leq 1$ components of the MetS syndrome. IR was evaluated by the hemostasis model assessment-insulin resistance (HOMA-IR) index, using the following equation: HOMA-IR = fasting insulin $(\mu \mathrm{U} /$ $\mathrm{mL}) \times$ fasting glucose $(\mathrm{mmol} / \mathrm{l}) / 22.5$; IR was defined as HOMA-IR $\geq 2.17$ among men and HOMA-IR $\geq 1.85$ among women [23].

Family history of premature CVD was defined as history of CVD among first degree female relatives aged $<$ 65 years or first degree male relative aged $<55$ years. Smoking status was stratified as smoker (current smokers) versus nonsmoker (including past and never smokers). Type 2 diabetes was defined as FPG $\geq 7 \mathrm{mmol} /$ L, $2 \mathrm{~h}$-PCPG $\geq 11.1 \mathrm{mmol} / \mathrm{L}$ or using anti-hyperglycemic drugs. Estimated glomerular filtration rate (eGFR) expressed as $\mathrm{mL} /$ minute $/ 1.73 \mathrm{~m}^{2}$, was estimated using the abbreviated prediction equation, calculated using the CKD Epidemiology Collaboration (CKD-EPI) equation [24]. CKD was defined as eGFR of $<60 \mathrm{ml} / \mathrm{min}$ per $1.73 \mathrm{~m}^{2}$ [25]. Being physically active was defined as individuals participating in vigorous physical activity at least three days per week for those who entered in the first phase of the TLGS. Those participants who entered the second phase, were considered physically active when achieving a minimum of at least 600 MET (metabolic equivalent task)-minutes per week [20].

Participants were classified into six phenotypes based on BMI category and metabolic health: 1) metabolically healthy normal weight, 2) metabolically healthy overweight, 3) metabolically healthy obese, 4) metabolically unhealthy normal weight, 5) metabolically unhealthy overweight and 6) metabolically unhealthy obese. We also used IR to define metabolic abnormalities. Similarly, six phenotypes were defined according to IR and different BMI categories.

\section{Statistical analysis}

All data are expressed as mean (SD) or median (interquartile range) for continuous variables and percentage for categorical ones. The mean difference [95\% Confidence interval $(\mathrm{CI})]$ of continuous variables and mean differences in the prevalence $[95 \% \mathrm{CI}]$ of each category of categorical variables were estimated to compare respondents with non-respondents i.e. missing data of covariates at the baseline or those without any follow up.

Differences of baseline characteristics between groups were analyzed using one-way ANOVA for continuous variables (Kruskal Wallis for HOMA-IR) and Chi-squared test for categorical ones. Event date was considered as the time of incident hypertension. Censoring time was defined as time point of leaving the residential area, death, loss to follow-up or end of study (19 January 2015), whichever occurred first. The event date for participants with incident hypertension was defined as mid-time between the date of the follow-up appointment at which hypertension was detected for the first time and the last follow-up visit before the diagnosis; for those with a negative event (censored subjects), the survival time was defined as the difference between the first and the last observation dates.

Cox's proportional hazard models were used to evaluate associations between different obesity phenotypes and development of incident hypertension, considering metabolically healthy normal weight as reference groups. Furthermore, these associations were evaluated using insulin sensitive normal weight individuals as reference groups.

Associations were evaluated in 3 models: Model 1, included age; Model 2 was further adjusted for current smoking status, low physical activity, diabetes mellitus, family history of premature CVD, eGFR, phase of recruitment and SBP and model 3; model 2 plus BMI.

In the multivariate analysis, the effect modifications of gender on the associations between different obesity phenotypes and incident hypertension were tested by entering the interaction terms (obesity phenotype $\times$ gender) in the model. There were significant effect modifications of gender on the metabolically healthy normal weight $(P=0.001)$, metabolically healthy overweight $(P=0.04)$, metabolically unhealthy overweight $(P=0.05)$ and metabolically unhealthy obese $(P=0.04)$ groups. Therefore, we stratified our analysis by gender. However, to make our finding comparable with those of other studies in this field, the analysis was also performed in the pooled sample which included sex as a covariate. Statistical significance was defined as a $p$-value of less than 
0.05 in a two-sided manner. Statistical analyses were conducted using Stata version 12.0 (Stata Corp LP, College Station, Texas).

\section{Results}

A total of 3659 participants $(m e n=1540)$ were evaluated. Baseline characteristics of respondent and non-respondent groups are compared in Additional file 1: Table S1, indicating no clinically important differences between respondent and non-respondent groups. Baseline characteristics of the study population among 6 different obesity phenotypes, defined by JIS criteria of metabolic syndrome, among men and women are presented in Tables 1 and 2, respectively. The mean (SD) of age, BMI, SBP and DBP among men were 40.0(13.32) years, $25.70(3.82) \mathrm{kg} / \mathrm{m}^{2}, \quad 113.99(11.0) \mathrm{mm}-\mathrm{Hg}$ and 74.26(8.22) $\mathrm{mm}-\mathrm{Hg}$, respectively; corresponding values among women were $38.20(11.65)$ years, $26.95(4.44) \mathrm{kg} / \mathrm{m}^{2}$, $110.71(11.54) \mathrm{mm}-\mathrm{Hg}$ and $73.80(7.97) \mathrm{mm}-\mathrm{Hg}$, respectively. Compared to metabolically healthy normal weight participants, generally, subjects with other obesity phenotypes in both sexes were older and had more unfavorable metabolic profiles, excluding similar low physical activity status among women.

During a median follow-up of 11.65 (interquartile range, 6.5) years, hypertension was observed in 493 men and 629 women (30.7\% of total population); corresponding incidence rates were 32.09 and 28.09 per 1000 person- years, respectively.

Table 3 presents the risk for hypertension among different obesity phenotypes defined by JIS criteria and IR among men and women. Considering JIS criteria to define metabolic health among men and women, metabolically healthy obesity as well as the metabolically unhealthy normal weight, overweight and obese groups were associated with greater risk of hypertension among men in the age adjusted model; moreover, metabolically unhealthy obese group showed a $63 \%$ greater risk considering covariates in model 2; however, these risks reached to null after further adjustment for BMI. In contrast, among women metabolically healthy obese, metabolically unhealthy normal weight, overweight and obese groups were associated with significant higher risk of hypertension even in the fully adjusted model [HR (95\%CI) of 1.96(1.16-3.32), 1.98(1.37-2.86), $2.08(1.49-2.90)$ and 2.06 (1.27-3.30), respectively].

Using IR to define the unhealthy metabolic status, higher risk of hypertension was seen among overweight and obese men with and without insulin resistance in the age adjusted model; furthermore, being obese with or without insulin resistance was associated with 46 and $62 \%$ higher risk for development of

Table 1 Baseline characteristics of study population based on combinations of body mass index and metabolic health defined by JIS criteria ${ }^{a}$ for men

\begin{tabular}{|c|c|c|c|c|c|c|c|c|}
\hline \multirow[b]{2}{*}{ Characteristics } & \multirow[b]{2}{*}{$\begin{array}{l}\text { Total } \\
(n=1540)\end{array}$} & \multicolumn{3}{|c|}{ Metabolically healthy $(n=457)$} & \multicolumn{3}{|c|}{ Metabolically unhealthy $(n=1083)$} & \multirow[b]{2}{*}{$\begin{array}{l}P \text {-value } \\
\text { (for trend) }\end{array}$} \\
\hline & & $\begin{array}{l}\text { Normal weight } \\
(n=369)\end{array}$ & $\begin{array}{l}\text { Overweight } \\
(n=81)\end{array}$ & $\begin{array}{l}\text { Obese } \\
(n=7)\end{array}$ & $\begin{array}{l}\text { Normal weight } \\
(n=322)\end{array}$ & $\begin{array}{l}\text { Overweight }(n= \\
568)\end{array}$ & $\begin{array}{l}\text { Obese } \\
(n=193)\end{array}$ & \\
\hline Age(years) & $40.0(13.32)$ & $35.49(13.39)$ & $38.30(12.92)$ & $42.28(14.47)$ & $41.22(13.95)$ & 41.94(12.62) & $41.42(12.30)$ & $<0.0001$ \\
\hline $\mathrm{BMI}\left(\mathrm{kg} / \mathrm{m}^{2}\right)$ & $25.70(3.82)$ & $21.91(1.73)$ & $26.30(1.16)$ & $32.89(4.04)$ & $22.94(1.59)$ & $27.34(1.36)$ & $32.22(2.69)$ & $<0.0001$ \\
\hline WC (cm) & $88.55(10.60)$ & $77.81(5.54)$ & $86.60(4.73)$ & 105.14(10.82) & $82.35(6.52)$ & $93.97(5.43)$ & 103.69(7.50) & $<0.0001$ \\
\hline $\mathrm{SBP}(\mathrm{mm}-\mathrm{Hg})$ & 113.99(11.00) & 108.24(9.67) & 111.55(9.31) & 116.57(8.38) & $115.08(11.86)$ & 116.16(10.55) & 117.70(9.62) & $<0.0001$ \\
\hline $\mathrm{DBP}(\mathrm{mm}-\mathrm{Hg})$ & $74.26(8.22)$ & $70.21(7.94)$ & $71.32(7.08)$ & $74.42(6.47)$ & $74.35(8.67)$ & $76.02(7.54)$ & $77.90(6.86)$ & $<0.0001$ \\
\hline Low Physical activity (\%) & $1452(68.5)$ & $249(67.5)$ & $55(67.9)$ & $4(57.1)$ & 228(70.8) & $400(70.4)$ & 148(76.7) & 0.002 \\
\hline Current smoker (\%) & $82(3.9)$ & $127(34.4)$ & 24(29.6) & $3(42.9)$ & $100(31.1)$ & 177(31.2) & $50(25.9)$ & 0.029 \\
\hline $\begin{array}{l}\text { Family history of premature } \\
\text { CAD (\%) }\end{array}$ & $334(15.4)$ & $38(10.3)$ & 11(13.6) & 0 & $37(11.5)$ & $83(14.6)$ & $36(18.7)$ & $<0.0001$ \\
\hline FPG (mmol/l) & $5.25(1.37)$ & $4.79(0.37)$ & $4.80(0.41)$ & $5.12(0.21)$ & $5.32(1.28)$ & $5.44(1.57)$ & $5.64(1.97)$ & $<0.0001$ \\
\hline $\begin{array}{l}\text { Total cholesterol } \\
(\mathrm{mmol} / \mathrm{l})\end{array}$ & $5.12(1.05)$ & $4.55(0.91)$ & 4.97(0.91) & $5.65(0.95)$ & $5.21(1.02)$ & $5.37(1.07)$ & $5.36(0.91)$ & $<0.0001$ \\
\hline $\mathrm{TG}(\mathrm{mmol} / \mathrm{l})$ & $1.97(1.27)$ & $1.07(0.33)$ & $1.24(0.29)$ & $1.18(0.22)$ & $2.14(1.07)$ & $2.43(1.51)$ & $2.43(1.14)$ & $<0.0001$ \\
\hline $\mathrm{HDL}-\mathrm{C}(\mathrm{mmol} / \mathrm{l})$ & $0.97(0.23)$ & $1.10(0.26)$ & $1.02(0.26)$ & $1.44(0.24)$ & $0.94(0.18)$ & $0.90(0.19)$ & $0.89(0.19)$ & $<0.0001$ \\
\hline $\operatorname{eGFR}\left(\mathrm{ml} / \mathrm{min} / 1.73 \mathrm{~m}^{2}\right)$ & $76.25(11.83)$ & 79.39(12.07) & 75.39(11.04) & $69.95(5.33)$ & $76.31(11.61)$ & $74.86(11.61)$ & $74.86(11.80)$ & $<0.0001$ \\
\hline HOMA-IR & $1.92(1.66)$ & $1.15(0.53)$ & 1.44(0.69) & $2.25(1.79)$ & $1.88(1.11)$ & $2.18(1.49)$ & $2.85(1.83)$ & $<0.0001$ \\
\hline
\end{tabular}

Values are expressed as mean \pm SD except median (interquartile range) for TG and HOMA-IR

JIS, Joint Interim Statement; BMI, body mass index; WC, waist circumference; SBP, systolic blood pressure; DBP, diastolic blood pressure; FPG, fasting plasma glucose; TG, triglyceride; HDL-C, High density lipoprotein-cholesterol; eGFR, estimated glomerular filtration rate; HOMA-IR, hemostasis model assessment-insulin resistance

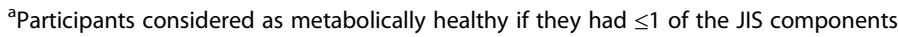


Table 2 Baseline characteristics of study population based on combinations of body mass index and metabolic health defined by JIS criteria ${ }^{\text {a }}$ for women

\begin{tabular}{|c|c|c|c|c|c|c|c|c|}
\hline \multirow[b]{2}{*}{ Characteristics } & \multirow[b]{2}{*}{$\begin{array}{l}\text { Total } \\
(n=2119)\end{array}$} & \multicolumn{3}{|c|}{ Metabolically healthy $(n=1231)$} & \multicolumn{3}{|c|}{ Metabolically unhealthy $(n=888)$} & \multirow[b]{2}{*}{$\begin{array}{l}P \text {-value } \\
\text { (for trend }\end{array}$} \\
\hline & & $\begin{array}{l}\text { Normal weight } \\
(n=629)\end{array}$ & $\begin{array}{l}\text { Overweight } \\
(n=473)\end{array}$ & $\begin{array}{l}\text { Obese } \\
(n=129)\end{array}$ & $\begin{array}{l}\text { Normal weight } \\
(n=130)\end{array}$ & $\begin{array}{l}\text { Overweight } \\
(n=388)\end{array}$ & $\begin{array}{l}\text { Obese } \\
(n=370)\end{array}$ & \\
\hline$\overline{\text { Age(years) }}$ & $38.20(11.65)$ & $32.08(10.43)$ & $36.57(10.07)$ & $40.41(10.95)$ & $42.36(12.72)$ & $42.67(11.01)$ & $43.74(10.59)$ & $<0.0001$ \\
\hline BMI $(\mathrm{kg} / \mathrm{m} 2)$ & 26.95(4.44) & $22.33(1.76)$ & $27.08(1.39)$ & $32.81(2.66)$ & $23.34(1.37)$ & $27.59(1.42)$ & $33.18(2.81)$ & $<0.0001$ \\
\hline WC $(\mathrm{cm})$ & $85.51(11.62)$ & $74.51(6.68)$ & $83.82(6.35)$ & $94.17(9.39)$ & $80.50(7.23)$ & $90.14(7.19)$ & $100.24(7.70)$ & $<0.0001$ \\
\hline $\mathrm{SBP}(\mathrm{mm}-\mathrm{Hg})$ & $110.71(11.54)$ & 105.39(10.48) & 108.74(9.94) & $111.37(8.75)$ & $114.41(13.63)$ & 114.82(11.39) & $116.45(10.72)$ & $<0.0001$ \\
\hline $\mathrm{DBP}(\mathrm{mm}-\mathrm{Hg})$ & $73.80(7.97)$ & $70.16(7.96)$ & $72.60(7.28)$ & $74.98(6.03)$ & $75.18(8.45)$ & $76.47(7.42)$ & $77.80(6.67)$ & $<0.0001$ \\
\hline Low Physical activity (\%) & 1084(70.4) & 439(69.8) & $302(63.8)$ & $88(68.2)$ & $93(71.5)$ & $267(68.8)$ & 263(71.1) & 0.304 \\
\hline Current smoker (\%) & $481(31.2)$ & $21(3.30)$ & 19(4.00) & $6(4.7)$ & $4(3.1)$ & 15(3.9) & $17(4.6)$ & 0.043 \\
\hline $\begin{array}{l}\text { Family history of } \\
\text { premature CAD (\%) }\end{array}$ & 205(13.3) & $83(13.2)$ & $66(14.00)$ & $28(21.7)$ & $17(13.1)$ & 75 (19.3) & $65(17.6)$ & 0.029 \\
\hline FPG (mmol/l) & $5.15(1.41)$ & $4.74(0.47)$ & 4.82(0.62) & $4.77(0.43)$ & $5.98(2.72)$ & $5.65(1.90)$ & $5.57(1.72)$ & $<0.0001$ \\
\hline $\begin{array}{l}\text { Total cholesterol } \\
(\mathrm{mmol} / \mathrm{l})\end{array}$ & $5.20(1.13)$ & $4.70(0.94)$ & $5.10(1.02)$ & $5.32(0.88)$ & $5.42(1.10)$ & $5.59(1.21)$ & $5.65(1.18)$ & $<0.0001$ \\
\hline $\mathrm{TG}(\mathrm{mmol} / \mathrm{l})$ & $1.60(0.99)$ & $1.04(0.47)$ & $1.22(0.60)$ & $1.21(0.36)$ & $2.22(1.02)$ & $2.30(1.12)$ & $2.19(1.14)$ & $<0.0001$ \\
\hline $\mathrm{HDL}-\mathrm{C}(\mathrm{mmol} / \mathrm{l})$ & $1.15(0.28)$ & $1.24(0.27)$ & $1.23(0.25)$ & $1.32(0.25)$ & $1.00(0.26)$ & $0.99(0.25)$ & $1.05(0.26)$ & $<0.0001$ \\
\hline eGFR (ml/min/1.73 m2) & $70.93(11.11)$ & $75.81(10.99)$ & $70.47(9.95)$ & 69.03(11.34) & $68.96(10.56)$ & $68.15(10.50)$ & $67.51(10.63)$ & $<0.0001$ \\
\hline HOMA-IR & $2.06(1.63)$ & $1.52(0.72)$ & $1.74(0.90)$ & $1.98(1.10)$ & $2.45(3.66)$ & $2.49(1.75)$ & $2.84(1.89)$ & $<0.0001$ \\
\hline
\end{tabular}

Values are expressed as mean \pm SD except median (interquartile range) for TG and HOMA-IR

JIS, Joint Interim Statement; BMI, body mass index; WC, waist circumference; SBP, systolic blood pressure; DBP, diastolic blood pressure; FPG, fasting plasma glucose; TG, triglyceride; HDL-C, High density lipoprotein-cholesterol; eGFR, estimated glomerular filtration rate; HOMA-IR, hemostasis model assessment-insulin resistance

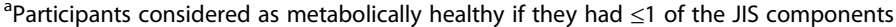

hypertension after adjustment with covariates in model 2 respectively, while all risks reached to null after further adjustment for BMI. Focusing on the women population, the adjusted HRs $(95 \% \mathrm{CI})$ for incident hypertension were $1.79(1.32-2.43)$ for insulin sensitive obese, 1.63(1.24-2.14) for insulin resistant overweight and 2.09(1.61-2.74) for insulin resistant obese groups, respectively considering covariates in model 2. These risks remained statistically significant in the insulin resistant overweight and obese groups in the fully adjusted model [HRs (95\% CI), 1.46(1.062.02 ) and 1.63(1.01-2.62), respectively].

As shown in Additional file 2: Table S2, generally the associations between obesity phenotypes with incident hypertension using JIS criteria for definitions of unhealthy metabolic status among the pooled sample using sex as another covariate were similar to those of the female population. However, focusing on IR in the pooled sample insulin sensitive obese, insulin resistant overweight and insulin resistant obese groups showed a significantly higher risk of 63, 42 and $90 \%$ after controlling for covariates in model 2, respectively. However, these risks attenuated and became insignificant after further adjustment for BMI (model 3).

\section{Discussion}

In this cohort study during over a decade long follow-up, for the first time, we examined the association of BMI and metabolic health status with incident hypertension separately among men and women, using different definitions of unhealthy metabolic status. We showed that considering JIS criteria to define metabolic health, only among women, the metabolically healthy obesity as well as the metabolically unhealthy groups were associated with $>95 \%$ greater risk for incident hypertension in the presence of important confounders, i.e. current smoking status, low physical activity, diabetes mellitus, family history of premature CVD, eGFR, phase of recruitment, SBP and BMI. Furthermore, considering the presence of insulin resistance for defining unhealthy status, only women in the insulin resistant overweight and obese groups showed significant and independent risk of hypertension.

The association between different obesity phenotypes and incident hypertension has been described in some previous studies, mostly conducted in East Asia [9-13]; nevertheless, direct comparison of our results with those of theirs might be difficult since first, there is no standard definition for metabolically healthy status; besides, different criteria and numbers 
Table 3 Risks for hypertension based on BMI and metabolic status as defined by MetS components or insulin resistance among men and women: Tehran lipid and Glucose study

\begin{tabular}{|c|c|c|c|c|c|c|c|}
\hline & \multirow[t]{2}{*}{$\mathrm{N}$ (event) } & \multicolumn{2}{|c|}{ Model $1^{a}$} & \multicolumn{2}{|c|}{ Model $2^{b}$} & \multicolumn{2}{|c|}{ Model $3^{c}$} \\
\hline & & $\mathrm{HR}$ & $95 \% \mathrm{Cl}$ & $\mathrm{HR}$ & $95 \% \mathrm{Cl}$ & $\mathrm{HR}$ & $95 \% \mathrm{Cl}$ \\
\hline \multicolumn{8}{|l|}{ Men } \\
\hline \multicolumn{8}{|l|}{ Defined by MetS components ${ }^{c}$} \\
\hline Metabolically healthy normal weight & $369(66)$ & 1.00 & & 1.00 & & 1.00 & \\
\hline Metabolically healthy overweight & $81(19)$ & 1.37 & $0.82-2.28$ & 1.19 & $0.71-1.99$ & 0.98 & $0.58-1.71$ \\
\hline Metabolically healthy obese & $7(3)$ & 3.20 & $1.00-10.21$ & 2.31 & $0.72-7.44$ & 1.53 & $0.44-5.29$ \\
\hline Metabolically unhealthy normal weight & $322(98)$ & 1.50 & $1.09-2.05$ & 1.07 & $0.78-1.48$ & 1.03 & $0.75-1.43$ \\
\hline Metabolically unhealthy overweight & $568(216)$ & 2.05 & $1.55-2.71$ & 1.32 & $0.98-1.76$ & 1.05 & $0.72-1.52$ \\
\hline Metabolically unhealthy obese & 193(91) & 2.65 & $1.93-3.64$ & 1.63 & $1.16-2.27$ & 1.06 & $0.61-1.83$ \\
\hline \multicolumn{8}{|l|}{ Defined by insulin resistance ${ }^{d}$} \\
\hline Insulin sensitive normal weight & $612(144)$ & 1.00 & & 1.00 & & 1.00 & \\
\hline Insulin sensitive overweight & $426(145)$ & 1.49 & $1.18-1.87$ & 1.21 & $0.96-1.53$ & 0.98 & $0.73-1.34$ \\
\hline Insulin sensitive obese & $84(38)$ & 1.88 & $1.31-2.69$ & 1.46 & $1.01-2.09$ & 0.95 & $0.54-1.66$ \\
\hline Normal weight with insulin resistance & $79(20)$ & 1.27 & $0.79-2.03$ & 0.88 & $0.55-1.43$ & 0.85 & $0.52-1.37$ \\
\hline Overweight with insulin resistance & 223(90) & 1.88 & $1.44-2.44$ & 1.26 & $0.95-1.66$ & 0.99 & $0.69-1.42$ \\
\hline Obese with insulin resistance & $116(56)$ & 2.44 & $1.79-3.33$ & 1.62 & $1.17-2.24$ & 1.04 & $0.60-1.78$ \\
\hline \multicolumn{8}{|l|}{ Women } \\
\hline \multicolumn{8}{|l|}{ Defined by MetS components ${ }^{c}$} \\
\hline Metabolically healthy normal weight & $629(75)$ & 1.00 & & 1.00 & & 1.00 & \\
\hline Metabolically healthy overweight & $473(81)$ & 1.19 & $0.86-1.63$ & 1.08 & $0.79-1.48$ & 0.99 & $0.69-1.41$ \\
\hline Metabolically healthy obese & $129(51)$ & 2.72 & $1.89-3.89$ & 2.42 & $1.69-3.48$ & 1.96 & $1.16-3.32$ \\
\hline Metabolically unhealthy normal weight & 130(54) & 2.73 & $1.91-3.90$ & 2.02 & $1.40-2.91$ & 1.98 & $1.37-2.86$ \\
\hline Metabolically unhealthy overweight & $388(168)$ & 3.14 & $2.38-4.15$ & 2.29 & $1.72-3.04$ & 2.08 & $1.49-2.90$ \\
\hline Metabolically unhealthy obese & $370(200)$ & 3.81 & $2.9-5.01$ & 2.55 & $1.92-3.38$ & 2.06 & $1.27-3.30$ \\
\hline \multicolumn{8}{|l|}{ Defined by insulin resistance } \\
\hline Insulin sensitive normal weight & $522(86)$ & 1.00 & & 1.00 & & 1.00 & \\
\hline Insulin sensitive overweight & 444(104) & 1.19 & $0.89-1.58$ & 1.09 & $0.82-1.46$ & 0.99 & $0.71-1.37$ \\
\hline Insulin sensitive obese & 183(85) & 2.17 & $1.61-2.94$ & 1.79 & $1.32-2.43$ & 1.42 & $0.89-2.27$ \\
\hline Normal weight with insulin resistance & 237(43) & 1.29 & $0.89-1.86$ & 1.15 & $0.79-1.67$ & 1.14 & $0.79-1.65$ \\
\hline Overweight with insulin resistance & $417(145)$ & 2.11 & $1.61-2.76$ & 1.63 & $1.24-2.14$ & 1.46 & $1.06-2.02$ \\
\hline Obese with insulin resistance & $316(166)$ & 3.04 & $2.34-3.96$ & 2.09 & $1.61-2.74$ & 1.63 & $1.01-2.62$ \\
\hline
\end{tabular}

MetS, metabolic syndrome; $B M I$, body mass index; $N$, number; $H R$, hazard ratio; $\mathrm{Cl}$, confidence interval

${ }^{a}$ Model 1, adjusted for age; ${ }^{b}$ Model 2, adjusted for model 1 plus current smoking status, low physical activity, diabetes mellitus, family history of premature CVD, SBP, Phase of recruitment and eGFR; ' ${ }^{c}$ Model 3, adjusted for model 2 plus BMI ${ }^{\text {P }}$ Participants considered as metabolically healthy if they had $\leq 1$ of the JIS components. ${ }^{\mathrm{d}}$ Insulin resistance was defined as a HOMA-IR $\geq 2.17$ among men and HOMA-IR $\geq 1.85$ among women [23].

of risk factors were applied to define metabolic health; moreover, confounders were not similar in their multivariable adjusted models; second, the differences in durations of follow-up between studies is another important factor affecting the study results. Third, we did not find any study that compared the impact of different BMI-metabolic status for incident hypertension in both genders in a cohort; in fact, all of the studies in this field were performed in a pooled sample.
Our study findings regarding the association between different obesity phenotypes defined by MetS components and consequent hypertension among the pooled sample were generally in line with those of other sex-adjusted prospective studies; the first study in this field conducted among Korean adults [11], concluded that the metabolically healthy obesity (i.e. obese population without any MetS components of ATP III criteria), was associated with a higher risk compared with the reference group (metabolically 
healthy normal weight). Moreover, another study of Chinese adults [9] concluded that the metabolically healthy overweight/obese groups (i.e., the absence of metabolic syndrome using International diabetes federation (IDF) criteria) were associated with greater risk of hypertension. Similarly, our study indicated that among the pooled sample, all obesity phenotypes were associated with higher risk of hypertension in the fully adjusted model, except for the metabolically healthy overweight group.

In another study conducted only among Korean men [13], metabolically healthy overweight and obese phenotypes as well as other unhealthy obesity phenotypes (according to the Wildman criteria) were associated with higher risk of hypertension. Authors concluded that both metabolic health status and being overweight or obese were independently associated with the risk of hypertension. In the current study among men, metabolically healthy obese as well as other unhealthy BMI categories were at higher risk of hypertension only before adjustment for potential confounding factors and these risks reached to null in the presence of wide set of covariates including baseline BMI.

To the best of our knowledge, two studies have examined the impact of combinations of BMI-metabolic health status on incident hypertension, using insulin resistance to define unhealthy metabolic status among adults without sex stratification $[10,12]$. One study conducted in Europe [12] on a population including middle-aged and elderly individuals showed that among normal weight subjects, being insulin resistant was not associated with development or progression of hypertension; whereas, being overweight and obese with and without insulin resistance increases the risk of hypertension and its progression. Hence, being overweight or obese might be harmful per se. In another study [10] using insulin resistance to define metabolic syndrome, metabolically healthy obese, metabolically unhealthy obese or non-obese groups were associated with higher risk of hypertension in the fully adjusted model, considering that researchers did not stratify the non-obese population into normal weight and overweight groups. In the current study, in the pooled sample insulin sensitive obese as well as insulin resistant overweight and obese groups showed a significant risk of 63,42 and $90 \%$ for CVD in the confounder adjusted model (model 2); however these risk were significantly attenuated after further adjustment for BMI.

Regarding the sex specific impact of IR on incident hypertension we have previously shown that among an Iranian population, after adjusting for potential confounders only women in the highest quartile of HOMA-IR had a significantly higher incidence of hypertension, compared with those in the lowest quartile [HR: 1.80 (95\% CI
1.31-2.40] [26]. In line with these results, the present study showed that only women, with insulin resistant overweight and obese phenotypes had a significant higher risk of hypertension in the fully adjusted model.

This higher impact of IR on hypertension risk among women compared to men, was recently addressed in a meta-analysis conducted by Feng Wangs et al. [27], showing an independent association between fasting insulin as well as IR with a more pronounced risk of hypertension, in women (relative risk (RR) 2.07 ; 95\% CI 1.19-3.60) than in men (RR 1.48; 95\% CI 1.17-1.88). Likewise, the study conducted by Petrie et al. [28] showed that in women (but not men) low insulin sensitivity, measured by the euglycemic clamp technique, was associated with higher levels of SBP over time, independent of key covariates including age, baseline blood pressure, BMI and change in BMI. The higher impact of IR in the development of hypertension among women, might be attributable to the effect of lower lean body mass in women; hence, fasting insulin or HOMA-IR values in women reflect a higher level of tissue IR [28]. On the other hand, other studies showed similar or higher impact of IR among men rather than women $[29,30]$. Considering the above findings, additional studies are required to investigate the mechanism for the difference in the association between IR and hypertension between genders.

Several strengths of this study include a large sample size with a long-term follow-up duration, adequate adjustment for potential confounders, reliable measurements of different covariates and last but not least a population sample representative of the Iranian population. We also examined the association between BMI and metabolic health status with incident hypertension for the first time among men and women separately using different definitions of unhealthy metabolic status. Of the limitations that should be noted, first, we did not assess changes of BMI and metabolic profiles during follow-up. Second, we did not evaluate some risk factors of hypertension, including family history of hypertension and dietary salt intake. Third, the statistically insignificant finding among metabolically healthy obese men group should be interpreted with caution due to the limited number of individuals and events, possibly leading to an unstable estimation. Fourth, as this study was performed in an Iranian population, its generalizability to other ethnicities might not be applicable.

In conclusion, our findings among an Iranian population showed that there were significant differences between genders in the association between obesity phenotypes and incident hypertension using different definitions. Generally, using JIS criteria, metabolically healthy obesity as well as all unhealthy obesity phenotypes were associated with about 2 fold higher risk of hypertension among women. Similarly, only among women, the presence of IR is a key promoter 
for the development of hypertension among those with $\mathrm{BMI}>25 \mathrm{~kg} / \mathrm{m}^{2}$. Moreover, in general, metabolic status defined by MetS components as compared to IR could do better in identifying high risk women for hypertension. Hence, women populations who are metabolically healthy obese using MetS definition or those with either $>1$ component of metabolic syndrome or overweight/obese ones with HOMA-IR $\geq 1.85$ should be prioritized for implementing urgent preventive strategies against hypertension focusing on lifestyle changes.

\section{Additional files}

Additional file 1: Table S1. Comparison of baseline characteristics between respondent and non-respondent groups: Tehran Lipid and Glucose Study. (DOCX 17 kb)

Additional file 2: Table S2. Risk for hypertension based on BMI and metabolic status as defined by MetS components or insulin resistance among the pooled sample: Tehran lipid and Glucose study. (DOCX 18 kb)

\section{Abbreviations}

2 h-PCPG: 2-h post challenge plasma glucose; BMl: Body mass index; CAD: Coronary artery disease; Cl: Confidence interval; CKD-EPI: Chronic kidney disease Epidemiology Collaboration; CVD: Cardiovascular diseases; DBP: Diastolic blood pressure; eGFR: Estimated glomerular filtration rate; FPG: Fasting plasma glucose; HDL-C: High density lipoprotein-cholesterol; HOMA-IR: Hemostasis model assessment-insulin resistance; HR: Hazard ratio; IDF: International diabetes federation; IR: Insulin resistance; JIS: Joint Interim Statement; LRC: Lipid Research Clinic; MAQ: Modifiable Activity Questionnaire; MET: Metabolic equivalent task; MetS: Metabolic syndrome; PAFs: Population attributable fractions; SBP: Systolic blood pressure; TC: Total cholesterol; TG: Triglyceride; TLGS: Tehran Lipid and Glucose Study; WC: Waist circumference

\section{Acknowledgements}

We would like to express our appreciation to the research team members and to TLGS participants for their enthusiastic support. The authors also wish to acknowledge Ms. Niloofar Shiva for critical editing of English grammar and syntax of the manuscript.

We would also like to thank Dr. Farhad Hosseinpanah for his helpful comments and advice on final draft.

\section{Funding}

This research did not receive any specific grant from funding agencies in the public, commercial, or not-for-profit sectors.

\section{Availability of data and materials}

Study data has been extracted from the Tehran Lipid and Glucose study (TLGS), a longitudinal and population-based prospective study performed on a representative sample of an urban population of Tehran (the capital of Iran). Statistical analyses have been performed with SPSS for windows version 20 and STATA version 12 and the statistical codes can be made available from the corresponding author on request.

\section{Authors' contributions}

$\mathrm{FH}, \mathrm{MK}$ and FA conceived of the presented idea. SA conducted the analyses. MK and FH developed the first draft of the manuscript. All authors contributed to the writing of the paper, and have read and approved the final manuscript.

\section{Ethics approval and consent to participate}

The study protocol was approved by the ethics committee of the Research Institute for Endocrine Sciences, Shahid Beheshti University of Medical Sciences, Tehran, Iran and all participants provided written informed consent.

\section{Consent for publication}

Not applicable.

\section{Competing interests}

The authors declare that they have no competing interests.

\section{Publisher's Note}

Springer Nature remains neutral with regard to jurisdictional claims in published maps and institutional affiliations.

\section{Author details}

${ }^{1}$ Metabolic Disorders Research Center, Golestan university of Medical Sciences, Gorgan, Iran. ${ }^{2}$ Prevention of Metabolic Disorders Research Center, Research Institute for Endocrine Sciences, Shahid Beheshti University of Medical Sciences, P.O. Box: 19395-4763, No. 24, Parvaneh Street, Velenjak, Tehran, Iran. ${ }^{3}$ Occupational Sleep Research Center, Baharloo Hospital, Tehran University of Medical Sciences, Tehran, Iran. ${ }^{4}$ Endocrine Research Center, Research Institute for Endocrine Sciences, Shahid Beheshti University of Medical Sciences, Tehran, Iran.

Received: 15 August 2018 Accepted: 11 February 2019

Published online: 27 February 2019

\section{References}

1. Collaboration NRF. Trends in adult body-mass index in 200 countries from 1975 to 2014: a pooled analysis of 1698 population-based measurement studies with 19. 2 million participants. Lancet. 2016;387:1377-96.

2. Azizi F, Azadbakht L, Mirmiran P. Trends in overweight, obesity and central fat accumulation among Tehranian adults between 1998-1999 and 20012002: Tehran lipid and glucose study. Ann Nutr Metab. 2005;49:3-8.

3. Rahmouni K, Correia ML, Haynes WG, Mark AL. Obesity-associated hypertension: new insights into mechanisms. Hypertension. 2005;45:9-14.

4. Sardarinia M, Akbarpour S, Lotfaliany M, Bagherzadeh-Khiabani F, Bozorgmanesh M, Sheikholeslami F, Azizi F, Hadaegh F. Risk factors for incidence of cardiovascular diseases and all-cause mortality in a middle eastern population over a decade follow-up: Tehran lipid and glucose study. PLoS One. 2016;11:e0167623.

5. Karelis AD, St-Pierre DH, Conus F, Rabasa-Lhoret R, Poehlman ET. Metabolic and body composition factors in subgroups of obesity: what do we know? The Journal of Clinical Endocrinology \& Metabolism. 2004;89:2569-75.

6. Kramer CK, Zinman B, Retnakaran R. Are metabolically healthy overweight and obesity benign conditions?: a systematic review and meta-analysis. Ann Intern Med. 2013;159:758-69.

7. Hamer M, Stamatakis E. Metabolically healthy obesity and risk of all-cause and cardiovascular disease mortality. The Journal of Clinical Endocrinology \& Metabolism. 2012;97:2482-8.

8. Leggio M, Lombardi M, Caldarone E, Severi P, D'Emidio S, Armeni M, Bravi V, Bendini MG, Mazza A. The relationship between obesity and hypertension: an updated comprehensive overview on vicious twins. Hypertens Res. 2017; 40:947.

9. Cao Z, Huang Y, Yu H, Yuan S, Tang B, Li Q, Li X, Yang X, He Q. Association between obesity phenotypes and incident hypertension among Chinese adults: a prospective cohort study. Public Health. 2017;149:65-70.

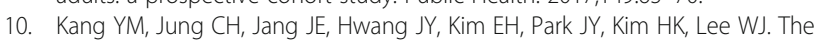
association of incident hypertension with metabolic health and obesity status: definition of metabolic health does not matter. Clin Endocrinol. 2016; 85:207-15.

11. Lee SK, Kim SH, Cho G-Y, Baik I, Lim HE, Park CG, Lee JB, Kim YH, Lim SY, Kim H. Obesity phenotype and incident hypertension: a prospective community-based cohort study. J Hypertens. 2013;31:145-51.

12. Lytsy P, Ingelsson E, Lind L, Ärnlöv J, Sundström J. Interplay of overweight and insulin resistance on hypertension development. J Hypertens. 2014;32: 834-9.

13. Ryoo J-H, Park SK, Oh C-M, Choi Y-J, Chung JY, Ham WT, Jung T: Evaluating the risk of hypertension according to the metabolic health status stratified by degree of obesity. Journal of the American Society of Hypertension 2017, 11:20-27. e24.

14. Hosseinpanah F, Mirbolouk M, Mossadeghkhah A, Barzin M, Serahati S, Delshad H, Azizi F. Incidence and potential risk factors of obesity among Tehranian adults. Prev Med. 2016;82:99-104.

15. Motlagh B, O'donnell M, Yusuf S. Prevalence of cardiovascular risk factors in the Middle East: a systematic review. Eur J Cardiovasc Prev Rehabil. 2009;16: 268-80. 
16. Alberti K, Eckel RH, Grundy SM, Zimmet PZ, Cleeman Jl, Donato KA, Fruchart J-C, James WPT, Loria CM, Smith SC. Harmonizing the metabolic syndrome: a joint interim statement of the international diabetes federation task force on epidemiology and prevention; national heart, lung, and blood institute; American heart association; world heart federation; international atherosclerosis society; and international association for the study of obesity. Circulation. 2009;120:1640-5.

17. Meigs JB, Wilson PW, Fox CS, Vasan RS, Nathan DM, Sullivan LM, D'agostino RB. Body mass index, metabolic syndrome, and risk of type 2 diabetes or cardiovascular disease. The Journal of Clinical Endocrinology \& Metabolism. 2006;91:2906-12.

18. Azizi F, Ghanbarian A, Momenan AA, Hadaegh F, Mirmiran P, Hedayati M, Mehrabi Y, Zahedi-Asl S. Prevention of non-communicable disease in a population in nutrition transition: Tehran lipid and glucose study phase II. Trials. 2009;10:5

19. Ainsworth BE, Jacobs JD, Leon AS. Validity and reliability of self-reported physical activity status: the lipid research clinics questionnaire. Med Sci Sports Exerc. 1993;25:92-8.

20. Guidelines for data processing and analysis of the International Physical Activity Questionnaire (IPAQ) — Short and Long Forms. Available at: https:// www.researchgate.net/file.PostFileLoader.html?id=5641f4c36143250eac8 b45b7\&assetKey=AS\%3A294237418606593\%401447163075131. Published November 2005

21. Esteghamati A, Abbasi M, Rashidi A, Meysamie A, Khalilzadeh O, Haghazali M, Asgari F, Nakhjavani M. Optimal waist circumference cut-offs for the diagnosis of metabolic syndrome in Iranian adults: results of the third national survey of risk factors of non-communicable diseases (SURFNCD2007). Diabet Med. 2009;26:745-6.

22. Azizi F, Khalili D, Aghajani H, Esteghamati A, Hosseinpanah F, Delavari A, Larijani B, Kelishadi R, Hadaegh F. Appropriate waist circumference cut-off points among Iranian adults: the first report of the Iranian National Committee of obesity. Archives of Iranian medicine. 2010;13:243.

23. Ghasemi A, Tohidi M, Derakhshan A, Hasheminia M, Azizi F, Hadaegh F. Cutoff points of homeostasis model assessment of insulin resistance, beta-cell function, and fasting serum insulin to identify future type 2 diabetes: Tehran lipid and glucose study. Acta Diabetol. 2015;52:905-15.

24. Levey AS, Stevens LA, Schmid CH, Zhang YL, Castro AF, Feldman HI, Kusek JW, Eggers P, Van Lente F, Greene T. A new equation to estimate glomerular filtration rate. Ann Intern Med. 2009;150:604-12.

25. Levey AS, Eckardt K-U, Tsukamoto Y, Levin A, Coresh J, Rossert J, Zeeuw DD, Hostetter TH, Lameire N, Eknoyan G. Definition and classification of chronic kidney disease: a position statement from kidney disease: improving global outcomes (KDIGO). Kidney Int. 2005;67:2089-100.

26. Arshi B, Tohidi M, Derakhshan A, Asgari S, Azizi F, Hadaegh F. Sex-specific relations between fasting insulin, insulin resistance and incident hypertension: 8.9 years follow-up in a middle-eastern population. J Hum Hypertens. 2015;29:260.

27. Wang F, Han L, Hu D. Fasting insulin, insulin resistance and risk of hypertension in the general population: a meta-analysis. Clin Chim Acta. 2017:464:57-63.

28. Petrie JR, Malik MO, Balkau B, Perry CG, Højlund K, Pataky Z, Nolan J, Ferrannini E, Natali A. Euglycemic clamp insulin sensitivity and longitudinal systolic blood PressureNovelty and significance: role of sex. Hypertension. 2013;62:404-9.

29. Kidambi S, Kotchen JM, Krishnaswami S, Grim CE, Kotchen TA. Hypertension, insulin resistance, and aldosterone: sex-specific relationships. The Journal of Clinical Hypertension. 2009;11:130-7.

30. Xun P, Liu K, Cao W, Sidney S, Williams OD, He K. Fasting insulin level is positively associated with incidence of hypertension among American young adults: a 20-year follow-up study. Diabetes Care. 2012;35:1532-7.

Ready to submit your research? Choose BMC and benefit from:

- fast, convenient online submission

- thorough peer review by experienced researchers in your field

- rapid publication on acceptance

- support for research data, including large and complex data types

- gold Open Access which fosters wider collaboration and increased citations

- maximum visibility for your research: over $100 \mathrm{M}$ website views per year

At BMC, research is always in progress.

Learn more biomedcentral.com/submissions 